Document downloaded from:

http://hdl.handle.net/10251/49692

This paper must be cited as:

Gil Salom, ML.; Soler Monreal, C. (2014). Writer's positioning in literature reviews in English and Spanish computing doctoral theses. Journal of English for Academic Purposes. 16:23-39. doi:10.1016/j.jeap.2014.08.002.

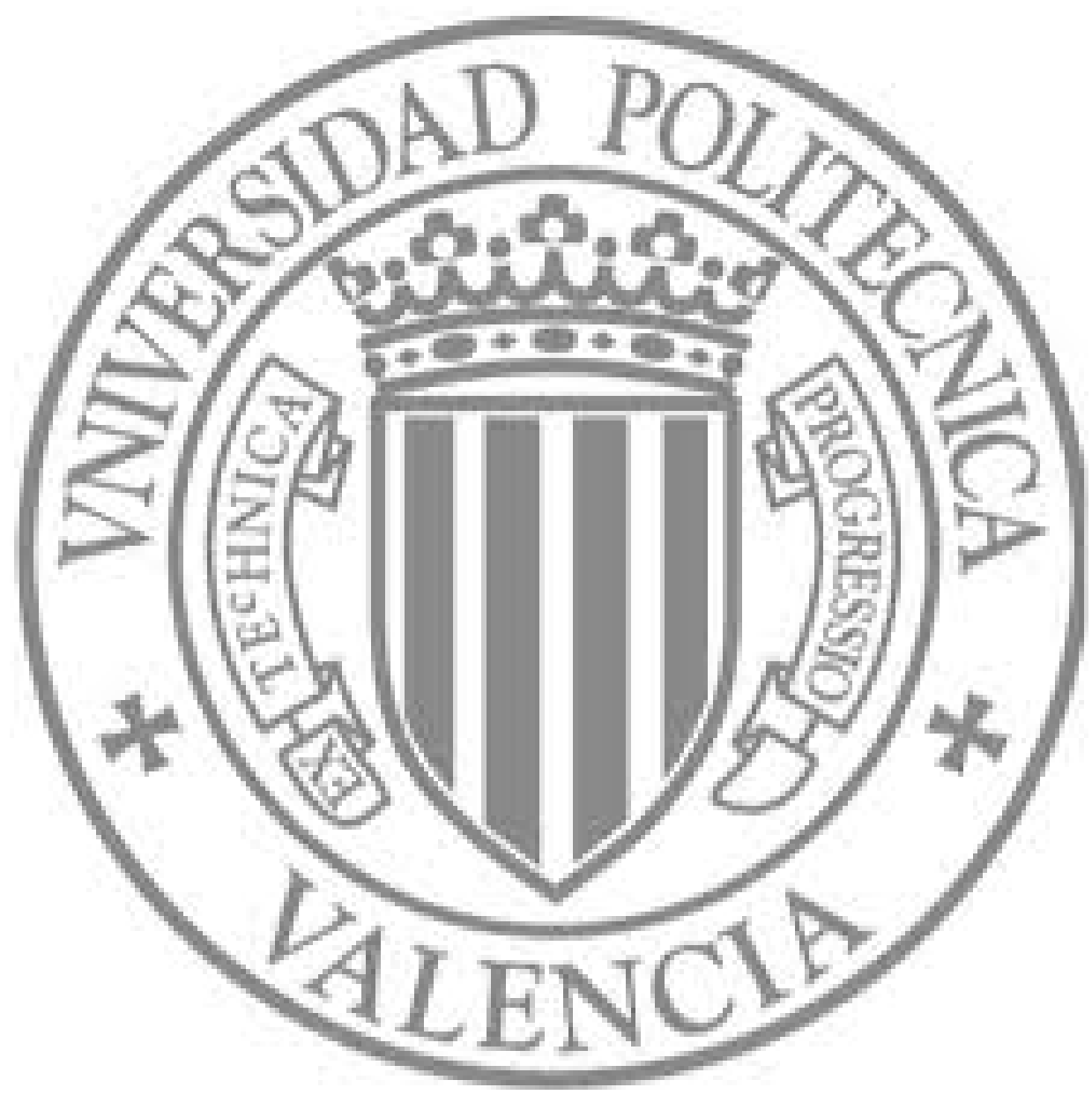

The final publication is available at

http://dx.doi.org/10.1016/j.jeap.2014.08.002

Copyright Elsevier 


\section{Writers' positioning in Literature Reviews in English and Spanish computing doctoral theses}

Luz Gil-Salom

Carmen Soler-Monreal

\section{Introduction}

Making appropriate reference to other texts is an essential feature of successful academic writing (Myers, 1990; Hyland, 2000, 2002; Thompson, 2005a; Petrić, 2007; Hewings, Lillis \& Vladimirou, 2010; Mansourizadeh \& Ahmad, 2011; Hu \& Wang, 2014; Kwan \& Chan, 2014). Writers are expected to integrate the ideas of others into their arguments, to indicate what is already known about their research area, or to point out the weaknesses in others' arguments, while aligning themselves with a particular disciplinary framework (Thompson \& Tribble, 2001; Kwan, 2008; Harwood, 2009). They are also required to demonstrate that they have made an original contribution to knowledge in the chosen field, which is in fact "the driving force of disciplinary activity” (Hyland, 2012a: 32). Studies on research articles (RAs) (Swales, 1990; Kwan, Chan \& Lam, 2012; Lim, 2012; Martín \& León Pérez, 2014) and PhD theses (Bunton, 2002; Thompson, 2005a, 2005b, 2009; Kwan, 2006; Ridley, 2011; Ono, 2012; Lim, Loi \& Hashim, 2014) have shown that reviewing previous research and justifying the study being reported are central rhetorical functions of introductions and literature reviews of research texts for obtaining acceptance and credibility.

When reporting the work of others, the source of the reported statement is important in the study of evaluation. According to Hunston (1993, 2003), the choice of source reflects a shared world between the writer and the reader, which is constructed with the ultimate aim of persuading the reader to accept the writer's position. The attitudinal assessment of content and the argumentative and metadiscoursive devices 
used to interact with readers are crucial persuasive strategies of academic communication.

The PhD thesis represents the first step in the academic career. The doctoral candidate must show that s/he knows the state-of-the-art of the field of study. At the same time, the research reported in the thesis must be shown to be relevant to the discipline (Bunton, 2002; Ridley, 2011). To achieve this purpose, thesis writers seek to adopt a tone of authority (Thompson, 2009), a dominant voice or position in the text, and evaluation seems to be a fundamental element to this goal. In displaying a command of the topic and projecting a position, these writers demonstrate an appropriate degree of autonomy while respecting the exigencies of the context of situation in which the thesis is elaborated (Hyland, 2012b). When reviewing the literature the writer's voice and stance guide the reader through the text by reporting what has been done previously and pointing at what still remains to be done. In doing so, writers use evaluative resources to convince readers of their authority. Thus, the final successful text results from the combination of linguistic elements of varied nature, which allows for the study of academic discourse from different perspectives. One of these perspectives explores interpersonal relationships in the text, i.e. the ways in which writers project themselves and consider their audience in discourse. Academic writers do not simply produce texts but use language to offer a credible representation of themselves and their work, and to establish social relations with readers. This concern with the interpersonal has related language use to its social, cultural and educational contexts (Hyland, 2004: 13).

The process of establishing connections between the writer's innovation and the work of predecessors on the topic under study is most manifest in the Literature Reviews (henceforth LRs) of $\mathrm{PhD}$ theses. LRs are background chapters that 
contextualise the thesis writer's research by describing previous research and the theoretical and methodological issues which are relevant to the topic in the thesis (Paltridge \& Starfield, 2007). This review leads to the indication of the gaps or needs in the disciplinary field that the thesis aimed to fill and makes it necessary to include critical comments on former studies in order to justify the validity of what is being presented. Thus, the main communicative purposes of LRs must be achieved not only through expository pieces of information but also through expressions of evaluation towards the propositional content in the text. The writer's stance towards reviewed authors' materials and her/his own research is constructed in the reported propositions and the writer's own claims. Indeed, citing another author involves the evaluation of that author, thus opening an "evaluative space" for writer comment (Thompson and Ye, 1991: 369). Writers highlight the strengths, weaknesses and omissions of existing literature, providing a critique of the research. Hence, the language used in a LR is often evaluative and demonstrates the writer's position about the literature in relation to her/his own work (Paltridge \& Starfield, 2007).

Critical evaluations in LRs reflect the writer's attitude towards the reviewed author's work, the writer's own work and the reader, who represents the discipline community they all belong to. In this social context, the linguistic expression of evaluation confers an interactive dimension on academic discourse. The writer's linguistic choices adjust the praise and criticism attached to a statement with the aim of building a convincing argument and having a persuasive effect on the reader.

A number of researchers have examined the ways of expressing and interpreting evaluation in academic genres from specific disciplines. These include Thompson \& Ye (1991) and Hyland (2000, 2002), who studied potentially evaluative reporting verbs used in academic papers, Stotesbury (2003), who analysed attitudinal language in RA 
abstracts, and Koutsantoni (2004), who explored appraisal resources in scientific RAs. There has also been an interest in the reasons for variation across languages in terms of evaluation (Mauranen, 1993; Vassileva, 2001; Yakhontova, 2002; Shaw, 2003; Fløttum, Dahl \& Kinn, 2006). As regards English and Spanish, Burgess (2002) and MartínMartín (2003) studied RA introductions and abstracts respectively, while Vázquez (2010) compared the use of modal verbs in the expression of epistemic stance in business management RAs. Recently, Martín \& León Pérez (2014) examined promotional strategies in a corpus of RA introductions in business management.

Among the studies in PhD theses, some research has been carried out recently on stance and voice (Charles, 2003, 2006, 2009; Thompson, 2005a, 2005b, 2012). A group of analyses have explored the structure and purposes of the introduction, LR and conclusion sections on theses produced by native English speaking writers (Ridley, 2000; Thompson, 2001, 2009; Bunton, 2002, 2005; Paltridge, 2002; Kwan, 2006; Flowerdew \& Forest, 2009; Peters, 2011). A second set of studies has focused on the contexts of situation and culture of doctoral research work, comparing writings subject to different traditions (Cooley \& Lewkowicz, 1997; Pecorari, 2006; LoCastro, 2008; Carbonell-Olivares, Gil-Salom \& Soler-Monreal, 2009; Lim, Loi \& Hashim, 2014).

Contrastive genre-based studies of $\mathrm{PhD}$ texts have compared the rhetorical organisation of English and Japanese introductory chapters of literature theses (Ono, 2012) and of computing thesis introductions written in English and in Spanish (SolerMonreal, Carbonell-Olivares \& Gil-Salom, 2011a). Citation practices in computing PhD LRs written in English and in Spanish have also been compared (Soler-Monreal \& GilSalom, 2011b). But to our best knowledge no contrastive analysis has been carried out on evaluative language in the LRs sections of $\mathrm{PhD}$ theses. Therefore, our interest in this study was first to explore the rhetorical structure of PhD LR sections, second, to 
identify the expression of evaluation in them and, finally, to compare the writers' strategies in theses written by native speakers of two different languages.

This article analyses the writer's attitude toward the validity, the worth and the significance of the information that is provided in a corpus of LRs in the applied field of computing written in English and in Spanish. Research in the area of computing science has focused on structural patterns (Cooper, 1985; Anthony 1999, 2001; Posteguillo, 1995, 1999) and rhetorical strategies (Kuo, 1999; Shehzad, 2006, 2007, 2008, 2010; Gil-Salom \& Soler-Monreal, 2010) of the genre of RAs. However, these aspects have not been investigated in computing doctoral work. Our purpose was to examine the differences between the LR sections of a corpus of 20 computing $\mathrm{PhD}$ theses in English and in Spanish by comparing realisations of personal judgement at both rhetorical and linguistic levels. The study sought to determine if these Spanish and English computing LRs exhibit a common rhetorical move structure and to describe the evaluative resources found in the moves of both sets of LRs.

Computing can be regarded as a highly anglicised discipline as it is driven mainly by developments in the US. The dominance of English as the international lingua franca of academia makes advances in the discipline known through publications in English. It can then be easily inferred that this discipline community knows and follows the conventions necessary to make a text publishable. English represents a competitive journal/conference culture, which makes writers visible internationally. A transfer of these conventions of scientific exposition in English to national language writing styles is certainly unavoidable. But are there any traces of the generic conventions of national styles in texts in computing written in other languages?

By studying doctoral theses written in Spanish, we aim to contribute to the study of an academic genre that has not been the object of empirical analysis in Spanish 
studies. We think that research based on two comparable corpora of English and Spanish can yield interesting cross-cultural results.

Traditionally, the English academic writing style is reader-oriented (Hinds, 1987): by explicitly using linguistic and rhetorical devices it helps to reader comprehension. Other cultures, however, like Eastern European cultures (Duszak, 1997; Flowerdew, 2001), are more writer-oriented: the writer provides information and arguments are conveyed in a more implicit way, which is more demanding for the reader. This writing style has been associated with implicit reader-responsible Spanish writing (Fernández Polo, 1999).

On the other hand, the notion of critical thinking is often in direct conflict with some cultural backgrounds and educational experiences (Paltridge \& Starfield, 2007). Although this is a culture-specific western norm, comments from the supervisors of the Spanish theses point out the danger of criticising people in authority. This does not mean that writers in Spanish are unable to critically evaluate other people's work, but it may influence how they do it.

Since the area of computing in Spain, as in the rest of the world, is strongly influenced by Anglo-American research and literature, one would expect to find similarities between the LRs written in Spanish and the rhetorical and evaluative patterns described for LRs in English, but also some differences, on account of the different writing cultures these languages belong to. The writers in English and the writers in Spanish may know what to communicate, but research on how they communicate is likely to give evidence of their different writing styles.

The results may provide insights for the syllabus design of doctoral writing courses. A genre-based approach could serve novice writers to relate the features of similar groups of texts to the contexts in which they are created or used and to the 
expectations of the audience. We hope that through the examination of actual texts they will benefit from guided inspection of how LRs work, which may be useful for individual research writing. Through conscious examination of evaluative resources and rhetorical choices, students can develop mastery of constructing effective interaction in their texts.

In section 2, we will describe the corpus, the conceptual framework and the evaluative parameters on which the analysis was based. In section 3 we will present cross-language differences and provide examples of evaluation used by the writers in the corpus.

\section{Method}

The corpus consists of 20 theses -10 in English and 10 in Spanish- written during the last decade. The theses were downloaded from the thesis repositories of the University of Glasgow, UK, and the Universitat Politècnica de València (UPV), Spain. The English texts were defended at the University of Glasgow. The Spanish texts were all defended at the UPV. All the theses were supervised by members of the Computing Science Departments of these universities. The diversity of research areas of interest in the field of computing brings about works on varied topics and methods, all of which are placed under the umbrella of computation and computer engineering.

The field was chosen because it is a relatively recent discipline which has evolved very rapidly and has assisted the increasing demands on information management, productivity improvement and data processing in a great variety of domains. The theses in the corpus deal with the following topics: allocation of resources and management techniques, web engineering, control systems, automation, problem-solving 
architectures and biological processing. In particular they propose the development of techniques, systems, architectures and resources that seek to improve previous models or solve perceived problems. So every topic is likely to evoke an evaluative stance on the part of the writer. As specialist informants of the Computing Department at the UPV have corroborated, the diversity does not prevent us from investigating the writing tendencies of computer scientists with different mother tongues with reference to the conventions of the genre. In fact, the contextual factors they share, namely the field of knowledge, the contents and organisation of the texts, the academic community, the intended audience, the writers' academic status, motivations and expectations and the circumstances leading to their production, make the texts comparable (Moreno, 2008; Golebiowski, 2011) and thus suitable for our research purposes.

The sections with headings referring explicitly to previous work were considered to be LRs and selected for analysis. In most theses, these sections constitute a single, or dedicated chapter (Ridley, 2011), after the introduction.

The resulting corpus consists of 355 pages of text for the 10 theses in English and 403 pages for the 10 theses in Spanish and a total of about 170,000 words. Tables 1 and 2 provide statistical data concerning the lengths of the theses and of their corresponding LR sections. They show that there is a wide range of dispersion in each group, which may be explained by the fact that there are different thesis formats, depending on the complex nature of the writer's research topics and the varied objects that have been studied. The figures may suggest that the English theses are more uniform than the Spanish theses under study. However, a larger corpus should be necessary to extrapolate these findings to the whole of doctoral work in computing in these two languages ( $p$ values indicate that the differences are not statistically significant). 
All in all, the space dedicated to the LR section in each thesis was found to be comparable (mean length of the LR sections in the English corpus: 35.5 pages, $17.3 \%$ of the whole text; mean length of the LR sections in the Spanish corpus: 40.3 pages, $17.7 \%$ of the whole text) and to allow for an empirical study on the sample, regardless of its heterogeneity.

Table 1. Length of the English and the Spanish theses: statistical data (T-test)

\begin{tabular}{|l|l|l|l|l|l|l|l|}
\hline & Mean & SD & Median & Min & Max & Kur & se \\
\hline $\begin{array}{l}\text { Theses in } \\
\text { English }\end{array}$ & 204.2 & 42.13 & 187 & 163 & 290 & -0.69 & 13.32 \\
\hline $\begin{array}{l}\text { Theses in } \\
\text { Spanish }\end{array}$ & 227.8 & 63.66 & 242 & 103 & 306 & -0.97 & 20.13 \\
\hline $\begin{array}{l}t \\
d f \\
p \text {-value }\end{array}$ & $\begin{array}{l}-0.9776 \\
18\end{array}$ & & & & & & \\
\hline
\end{tabular}

Table 2. Length of the English and the Spanish LRs: statistical data (T-test)

\begin{tabular}{|l|l|l|l|l|l|l|l|}
\hline & Mean & SD & Median & Min & Max & Kur & se \\
\hline $\begin{array}{l}\text { LRs in } \\
\text { English }\end{array}$ & 35.5 & 16.79 & 37 & 13 & 67 & 1.10 & 5.31 \\
\hline $\begin{array}{l}\text { LRs in } \\
\text { Spanish }\end{array}$ & 40.3 & 36.05 & 31 & 5 & 104 & -1.35 & 11.40 \\
\hline $\begin{array}{l}t \\
d f \\
p \text {-value }\end{array}$ & $\begin{array}{l}0.3728 \\
0.7136\end{array}$ & & & & & & \\
\hline
\end{tabular}

Each LR was analysed intuitively using a functional-semantic approach. The functional analysis was framed using Kwan’s (2006) move-strategy model (see Table 3). Kwan used Swales' CARS (1990) model for RA introductions as a reference to study the structure of PhD LR sections in applied linguistics. She developed and modified the CARS model to adjust it to her findings. Following Bhatia (2001), she specifically used the term strategy instead of Swales' step for the sub-components of the moves and further developed the writer's choices to create the niche for the research 
presented in the thesis. The moves and their respective strategies were identified and coded manually in each text segment of the LRs under study.

Table 3. Kwan’s (2006) move structure for the thematic units in LR chapters of applied linguistics PhD theses

\begin{tabular}{ll}
\hline Move 1 & Establishing one part of the territory of one's own research by: \\
\hline Strategy A & surveying the non-research-related phenomena or knowledge claims \\
Strategy B & claiming centrality \\
Strategy C & surveying the research-related phenomena \\
\hline Move 2 & Creating a research niche (in response to Move 1) by: \\
\hline Strategy A & counter-claiming \\
Strategy B & gap-indicating \\
Strategy C & asserting confirmative claims about knowledge or research practices surveyed \\
Strategy D & asserting the relevancy of the surveyed claims to one's own research \\
Strategy E & abstracting or synthesising knowledge claims to establish a theoretical position \\
& or a theoretical framework \\
\hline Move 3 (optional) & Occupying the research niche by announcing: \\
\hline Strategy A & research aims, focuses, research questions or hypotheses \\
Strategy B & theoretical positions/theoretical frameworks \\
Strategy C & research design/processes \\
Strategy D & interpretations of terminology used in the thesis \\
\hline
\end{tabular}

The semantic analysis of the corpus searched LRs to trace realisations of explicit evaluation which added personal voice to the propositional content in the discourse. Focus was placed on the evaluation of others' work and the novel research, where the writer can be seen to interact with the research community by reporting on the topic which is discussed or guiding it in the interpretation of the results of the research. It is worth noting that "topic-oriented evaluation" (Thetela, 1997: 104), which refers to generalised categories of value established in the discipline for the area under investigation rather than to the outcome of the research itself, was not considered in this study. For instance, the following examples present the subject as a problem or an issue difficult to solve. They are topic-oriented as they ascribe a value to the topic but do not reflect the writer's personal judgement:

Presentations made in online environments are often made at a distance over either time or space and often across both. This makes it difficult for individuals to backup any claims they might make about themselves in a timely fashion. In Joinson's study of 
Facebook2 users [86] this problem is noted and he highlights how players construct profiles that 'show' their characteristics and traits rather than profiles that 'tell' people that they have particular characteristics and traits. TE5

Una posible solución al problema de optimización no convexa que se plantea es la utilización de programación Quadrática Sequencial (SQP) [Camacho \& Bordons 2004]. TS5

/A possible solution to the problem of non-convex optimisation posed is the utilization of Sequential Quadratic Programming (SQP) [Camacho \& Bordons 2004]. TS5/

Lexical, syntactic, discourse-based items and modals were identified and counted and their frequency of occurrence was calculated in percentages of total evaluative devices found in each corpus. We took as a reference Stotesbury's (2003) suggestions and Koutsantoni's (2004) taxonomy of attitude, certainty and common knowledge markers and elaborated our own list with the items we identified in the corpus as means of expressing personal attitude and judgement. We focused on four categories of markers: attitude, certainty, epistemic modality and discourse-based markers.

The label attitude markers was used by Koutsantoni to refer to the writer's affective values and their appreciation of the propositional content, models, methods or approaches. Attitude markers add a positive or negative judgement to the sentence and impose it on readers, with the aim of guiding them into seeing the propositional content in this way (Koutsantoni, 2004: 169). In this study, attitude markers comprise explicitly evaluative lexis: evaluative adjectives, evaluative nouns, evaluative and intensifying adverbs, and evaluative verbs.

We categorised adjectives and adverbs expressing the writer's certainty and full commitment to the truth value of the proposition as certainty markers. They are another linguistic means of explicitly imposing views on readers and working towards the acceptance of claims as they do not allow room for disagreement and regard readers as passive recipients of ideas unable to make their own evaluations and judgements (Koutsantoni, 2004: 173). In contrast, epistemic modality needs the interplay of the 
cotext, the context and the content to be interpreted as overtly evaluative. However, since the strategy assumes similar persuasive purposes, we estimated it represents a type of evaluation (Stotesbury, 2003). Epistemic modality markers reduce the writer's commitment and mitigate the imposition on readers, which allows them to feel free to judge differently. We took into account modals and epistemic adjectives and adverbs.

Apart from lexical realisations of explicit evaluation, less explicitly evaluative discourse-based expressions can also express personal attitude towards propositions. Although Koutsantoni classified them as types of attitude markers, we agree with Stotesbury that discourse-based markers deserve a study of their own as expressions of evaluation, especially negative evaluation. In conjunction with the context, they represent a resource through which explicit evaluation can be traced (Stotesbury, 2003: 336). In this study, discourse-based markers include negative expressions, adversatives and sentence disjuncts. They signal limitations, problems or gaps in knowledge and convey negative judgements of previous models, techniques and results, thus leading the reader to agree that more research is needed and to accept the writer's claim (Koutsantoni, 2004: 172).

\section{Results}

\subsection{Move structure of the Spanish and the English LRs}

The analysis revealed that there were not any significant structural differences between the English and the Spanish computing LRs that were examined in the study. It confirmed the presence in the corpus of the three moves of Kwan's model, despite the different results for each set of LRs. Table 4 shows the number of theses that use each of Kwan's (2006) move and strategy in each set of LRs. The ten LRs in the English set 
use the Move1-Move2-Move3 structure. The majority of the Spanish LRs use also the Move1-Move2-Move3 model, although two theses have a Move1-Move2 pattern. Due to the length of the section and the number of items reviewed, Move 1 and Move 2 are used recursively along the LRs. However, naming the thesis work (Move 3) is granted much less space than the other two moves and is not recurrent in all the LRs.

Table 4 also shows that all the strategies in Kwan’s (2006) model were identified. It also includes a new strategy found in the analysis of the texts under study and referring to the writer's contribution to research (Strategy $\mathrm{E}$ in Move 3, in italics).

According to these data, we can infer that the LRs in both languages follow similar rhetorical patterns. However, differences emerge if we compare the range of strategies used in each corpus. Although the comparison of the results for Move 1 shows similarities between both sets of theses, differences in the use of strategies for Moves 2 and 3 are evident. It was found that the Spanish LRs use fewer strategies for the realisation of Moves 2 and 3 than the English LRs. These results corroborate previous comparative studies which concluded that the English texts conform to international rhetorical conventions to a greater extent than the Spanish texts (Sheldon, 2011; Martín \& León Pérez, 2014).

Examples in the Appendix illustrate these strategies found in the corpus.

Table 4. Move structure of the LRs in English and Spanish

\begin{tabular}{lcc}
\hline Move & English n & Spanish n \\
\hline Move 1 Establishing one part of the territory of one’s own research & $\mathbf{1 0}$ & $\mathbf{1 0}$ \\
\hline $\begin{array}{l}\text { Strategy 1A: surveying the non-research-related phenomena or knowledge } \\
\text { claims }\end{array}$ & 10 & 9 \\
Strategy 1B: claiming centrality & 6 & 6 \\
Strategy 1C: surveying the research-related phenomena & 10 & 10 \\
\hline Move 2 Creating a research niche (in response to M1) & $\mathbf{1 0}$ & $\mathbf{1 0}$ \\
\hline Strategy 2A: counter-claiming & 10 & 8 \\
Strategy 2B: gap-indicating & 10 & 6 \\
Strategy 2C: asserting confirmative claims about knowledge or research & 10 & 3 \\
practices surveyed & &
\end{tabular}


Strategy 2D: asserting the relevancy of the surveyed claims to one's own

Strategy 2E: abstracting or synthesising knowledge claims to establish a

\begin{tabular}{lcc}
\hline Move 3 Occupying the research niche by announcing & $\mathbf{1 0}$ & $\mathbf{8}$ \\
\hline Strategy 3A: research aims, focuses, research questions or hypotheses & 6 & 5 \\
Strategy 3B: theoretical positions/theoretical frameworks & 2 & 1 \\
Strategy 3C: research design/processes & 6 & 5 \\
Strategy 3D: interpretations of terminology used in the thesis & 2 & 1 \\
Strategy 3E: contribution to research & 3 & 1 \\
\hline
\end{tabular}

\subsubsection{Move 1 in the English and the Spanish LRs}

As mentioned above, all the LRs in the corpus use Move 1 Establishing one part of the territory of one's own research. Moreover, Strategy 1A surveying the nonresearch-related phenomena or knowledge claims and Strategy $1 \mathrm{C}$ surveying the research-related phenomena are most commonly used. Table 4 shows that the ten theses in the Spanish corpus use Strategy 1C and nine theses use Strategy 1A. In the English LRs both strategies are used in the ten theses that make up the corpus. Strategy 1B claiming centrality is not used so frequently (in six out of 10 theses in each corpus).

\subsubsection{Move 2 in the English and the Spanish LRs}

Both sets of theses create a niche in research (Move 2), which serves to justify the thesis original contribution. The differences between the two groups of theses emerge when we examine the strategies used to clearly establish the niche. The English LRs use a wider range of strategies in Move 2. All of them use Strategies 2A counter-claiming, 2B gap-indicating, 2C asserting confirmative claims about knowledge or research practices surveyed and 2E abstracting or synthesising the strengths and weaknesses of previous achievements. And nine English texts use Strategy 2D asserting the relevancy of the surveyed claims to one's own research. However, the Spanish texts do not use all four strategies, in fact two of them do not use Strategy 2A, four LRs do not use Strategy 
2B nor Strategy 2E or 2D and only three LRs use Strategy 2C. In the Spanish set of LRs, Move 2 is typically created by using Strategy 2A counter-claiming (in eight theses) and/or Strategy 2B indicating a gap or need in previous research solutions or proposals (in six theses), after having offered a survey of previous research, which leads to recurrent Move1-Move2 cycles and explains the use of Strategy 2E abstracting or synthesising the strengths and weaknesses of previous achievements (in six theses). In other cases, the validity of previous approaches and their relevancy to the writer's research is asserted (mainly with Strategy 2D, used in six Spanish LRs, and less frequently with Strategy 2C, used in only three Spanish LRs).

In both corpora we find instances in which the writer, after having reviewed a technique, approach, scheme or tool, either evaluates it or reports on others' evaluation so as to create the niche which explains subsequent research associated with the cited one. In these cases, Move 2 can be considered to be a move embedded in Move 1 (Carbonell-Olivares, Gil-Salom \& Soler-Monreal, 2009), rather than an independent move where there is an indication of a gap or a need of further research or of new applications or systems, thus preparing the way for announcing the present research.

\subsubsection{Move 3 in the English and the Spanish LRs}

As Table 4 shows, Move 3 is used in the 10 English LRs but in only eight Spanish texts. It is typically found at the beginning and at the end of the LR sections and it occupies much less space than the other two moves. It seems that the thesis writers in Spanish do not consider it to be an essential component of a LR, although this should be confirmed with the study of a larger corpus. Move 3 typically consists of a statement after Move 2 in which the author mainly announces the research aims or focuses (Strategy 3A) or specifies the research process (Strategy 3C). However, in order to 
make the thesis work relevant, the contribution to research is also explained (Strategy 3E contribution to research). As seen for Move 2, the English corpus shows that doctoral writers use a wider range of strategies in their theses with the purpose of occupying the research niche.

\subsection{Evaluative devices}

This study also aimed at comparing instances of evaluation used in the strategies found in the two selected sets of LRs. Table 5 shows the number of theses that use each of the markers under study in each set of LRs. It reveals that most of the English LRs display more varied resources than the Spanish LRs. It also shows that evaluation is carried out mainly through attitude markers in both corpora. Epistemic modality and a variety of discourse-based markers are also typically found in the English LRs while the Spanish LRs seem to rely mainly on adversatives. However, non-parametric tests showed that differences were non-significant (Sig. 1,000 for each independent group). It would be necessary to analyse a larger sample to expect significant statistical differences.

Table 5. Evaluative devices in the English and in the Spanish LRs

\begin{tabular}{l|c|c}
\hline Category & English LRs n & Spanish LRs n \\
\hline Attitude markers & $\mathbf{1 0}$ & $\mathbf{1 0}$ \\
\hline Evaluative adjectives & 10 & 10 \\
Evaluative nouns & 10 & 10 \\
Evaluative adverbs & 9 & 5 \\
Evaluative verbs & 10 & 10 \\
Intensifying adverbs & 10 & 6 \\
\hline Certainty markers & $\mathbf{6}$ & $\mathbf{6}$ \\
\hline Epistemic modality markers & $\mathbf{9}$ & $\mathbf{5}$ \\
\hline Discourse-based markers & $\mathbf{1 0}$ & $\mathbf{9}$ \\
\hline Negative expressions & 10 & 5 \\
Adversatives & 10 & 8 \\
Disjuncts & 7 & 3 \\
\hline
\end{tabular}


As stated above, the English and the Spanish writers' evaluative voices are heard explicitly through attitude markers. Evaluative adjectives, nouns and verbs are by far the most frequently occurring linguistic categories of attitude markers in the Spanish corpus. The English LRs seem to use all evaluative categories more consistently. They also use adjectives in their comparative and superlative forms and more often highlight their meaning with intensifying adverbs.

Discourse based markers are also frequently used in the two sets. Negative expressions and adversatives are combined by all the writers in English while the writers in Spanish mainly use adversatives. As for certainty and epistemic modality, the results in Table 5 show that epistemic modality markers are preferred by the English writers. The Spanish writers, on the other hand, do not show a clear preference for either certainty or epistemic modality markers to present their viewpoints (six and five LRs respectively).

Table 6. Evaluative devices in the English and in the Spanish LRs (\% of total evaluative devices found in each set of theses)

\begin{tabular}{l|c|c}
\hline Category & English LRs & Spanish LRs \\
\hline Attitude markers & $\mathbf{7 2 . 9}$ & $\mathbf{7 4 . 5}$ \\
\hline Evaluative adjectives & 31.1 & 40 \\
Evaluative nouns & 16.2 & 19.9 \\
Evaluative adverbs & 2.4 & 1.4 \\
Evaluative verbs & 8.3 & 4.2 \\
Intensifying adverbs & 17.1 & 9 \\
\hline Certainty markers & $\mathbf{1 . 6}$ & $\mathbf{5}$ \\
\hline Epistemic modality markers & $\mathbf{1 2 . 6}$ & $\mathbf{4 . 4}$ \\
\hline Discourse-based markers & $\mathbf{1 0 . 5}$ & $\mathbf{1 3 . 9}$ \\
\hline Negative expressions & 5.1 & 6.2 \\
Adversatives & 5.1 & 5.9 \\
Disjuncts & 0.2 & 1.4 \\
\hline
\end{tabular}

If we compare the percentage of each group of evaluative devices out of the total of evaluative devices found in each set of LRs (Table 6), we can see that, in general, the figures are in line with the data found in Table 3. However, Table 6 shows interesting 
results which cannot be explained only by individual writing styles in both languages. For example, although certainty markers are used in six LRs in both sets of theses, their percentage is almost three times higher in the Spanish corpus than in the English corpus. Indeed, few certainty markers have been found in the English corpus in comparison to the number of other evaluative devices, which may indicate that, unlike the Spanish writers, the English writers consider this is not an essential resource to interact with the reader. On the other hand, the percentage of epistemic modality markers is almost three times higher in the English corpus than in the Spanish set, which seems to indicate that five Spanish writers do not make a point of being deferential to the reader.

Samples of the evaluative items found in the different categories in both the English and the Spanish LRs are provided in Table 7. These devices can be found in the three moves and in most of the strategies used in the LRs. Their lexical values and contextual aspects determine whether they show appraisal or reject aspects of existing research. In the following subsections, examples of lexical and discourse-based realisations of markers and their pragmatic use in the two sets of LRs are commented upon.

Table 7. Most frequently used evaluative devices in the English and the Spanish LRs

\begin{tabular}{l|l|l}
\hline Category & \multicolumn{1}{c}{ English LRs } & \multicolumn{1}{c}{ Spanish LRs } \\
\hline Attitude markers & \multicolumn{1}{|c}{$\begin{array}{l}\text { important, useful, significant, } \\
\text { effective, interesting } \\
\text { importance, interest, contribution, } \\
\text { effectiveness, potential, attention } \\
\text { appropriately, importantly, well }\end{array}$} & $\begin{array}{l}\text { importante, principal, relevante, } \\
\text { eficaz, eficiente } \\
\text { ventajas, éxito, interés, } \\
\text { importancia, clave, eficiencia } \\
\text { bien, notablemente, } \\
\text { significativamente } \\
\text { apoyar, demostrar, mejorar, } \\
\text { destacar } \\
\text { muy, bastante, prácticamente, } \\
\text { poco, suficientemente }\end{array}$ \\
Evaluative verbs & $\begin{array}{l}\text { outperform, highlight, improve, } \\
\text { enhance, achieve } \\
\text { extremely, widely, particularly, } \\
\text { very, greatly }\end{array}$ & $\begin{array}{l}\text { claramente, obviamente, sin duda, } \\
\text { patente, clara }\end{array}$ \\
\hline Certainty markers & $\begin{array}{l}\text { clear, apparent, evident, clearly, } \\
\text { unsurprisingly, evidently, certainly }\end{array}$ & puede, parece que \\
\hline $\begin{array}{l}\text { Epistemic modality } \\
\text { markers }\end{array}$ & $\begin{array}{l}\text { can, could, might, should, may, } \\
\text { seem, must, possibly }\end{array}$ & \multicolumn{1}{l}{18}
\end{tabular}




\begin{tabular}{l|l|l}
\hline Negative expressions & $\begin{array}{l}\text { do not account for; did not grasp; } \\
\text { does not involve } \\
\text { however, even though, } \\
\text { nevertheless, while } \\
\text { unfortunately, hopefully, } \\
\text { unsurprisingly }\end{array}$ & $\begin{array}{l}\text { no ofrecen, no aplican, no es fácil, } \\
\text { no consigue, no hay, } \\
\text { sin embargo, aunque, pero, } \\
\text { mientras, si bien, aun, sino } \\
\text { afortunadamente, de hecho, por } \\
\text { supuesto }\end{array}$ \\
\hline
\end{tabular}

\subsubsection{Praising}

In Move 1, evaluative lexis is particularly common when previous research is reviewed (Strategy 1C) and the centrality of the theme is claimed (Strategy 1B). The acceptance of previous research in Move 1 is expressed explicitly through positive evaluation. This includes claims of significance, power, efficiency, simplicity, good performance and novelty of others' achievements. Examination of the lexis has shown that terms with equivalent values are used in both languages.

According to the values of the discipline community, praising adjectives meaning importance are, inter alia, English important, significant, interesting, relevant, consistent and vital, and Spanish importante, relevante, principal, significativo, notable and sustancial.

(1) In [113] Robinson states, "The dimension of implicit, formal or conventionally readable "states" is essential as it provides a common reference point for participants. A sort of 'external world' that can be pointed at, and whose behaviour is rule-governed and predictable. But this 'world' is meaningless without interpretation, without the talking that maintains its meaning”. This predictability is extremely important to our understanding of the world that we live in. TE5

(2) El proceso de modelado e identificación de modelos matemáticos de sistemas, tema de importancia muy relevante en muchas disciplinas de la ciencia y la ingeniería, se vuelve especialmente complicado al tratar con sistemas no lineales (Johansson, 1993).TS8

/The process of modeling and identification of mathematical system models, a very relevant issue in many scientific and engineering disciplines, becomes especially complex when dealing with non-linear systems (Johansson, 1993).TS8/

With the meaning of power we can mention English influential and Spanish influyente, fuerte and potente. 
(3) Probably the most influential of such statements in HCI was proposed by Shneiderman in his Visual Information Seeking Mantra [138] [...]. TE3

(4) Si el modelado de sistemas no lineales con el uso de herramientas basadas en la teoría de los conjuntos borrosos (el llamado modelado borroso) se ha revelado como una potente arma en los casos en los que no se tiene un conocimiento profundo del sistema a estudiar, o el que se tiene es heurístico o impreciso, su combinación con las técnicas de agrupamiento [...] hacen que este aspecto del modelado tenga un futuro muy prometedor. TS8

/If the modeling of non-linear systems using tools based on the theory of fuzzy sets (the so-called fuzzy modeling) has revealed itself as a powerful tool in the cases where there is no deep knowledge of the system under study, or this knowledge is heuristic or imprecise, its combination with grouping techniques make this aspect of modeling very promising for the future. / open very promising future prospects for this aspect of modeling.TS8/

Other praising adjectives in Spanish LRs belong to the simplicity domain (e.g. sencillo, simple).

(5) Las plantillas (Wang, 1994) constituyen un método heurístico simple y eficaz para diseñar sistemas borrosos desde datos entrada-salida, que se desarrolla en cinco pasos.TS8

/Templates (Wang, 1994) constitute a simple and effective heuristic model for designing fuzzy systems from input-output data, which is developed in five steps. TS8/

Novelty and good performance are also characteristics used to modify nouns with

the writer's judgement. Adjectives such as English novel, successful, effective, attractive and fruitful and Spanish innovador, nuevo, novedoso, diferente, exitoso, excelente, satisfactorio and capaz, are common in both corpora.

(6) Tree-Maps are very effective visualisation techniques in biology, where a high volume of data could be represented within a small area. TE4

(7) A pesar de que las técnicas Soft Computing se encuentran en pleno desarrollo, muchas instituciones de investigación, industrias y firmas comerciales han comenzado a aplicar estas novedosas herramientas a problemas complejos de diversa índole [Kecman, 2001]. TS4

/Although Soft Computing techniques are still being developed, many research institutions, industries and commercial firms have begun to apply these novel tools to complex problems of many different kinds. [Kecman, 2001]. TS4/

These evaluative adjectives are found in their comparative and superlative forms

when different models or techniques are commented upon.

(8) Los algoritmos evolutivos son los que mejores resultados han dado en este caso. TS7

/Evolutive algorithms have provided the best results in this case. TS7/ 
Evaluative nouns are also a prevalent means of evaluation. Many of them refer to the advantages (e.g. English improvement, benefit and solution and Spanish ventajas, beneficios and virtudes), and the characteristics positively valued by the community (e.g. English effectiveness, consistency, usefulness and versatility and Spanish rendimiento, calidad, eficiencia, sencillez and rapidez).

(9) His method takes into account the relative position of clicks in a result list as training data. The experimental results show a clear improvement in web search experience from the use of clickthrough data. TE10

(10) The constraint solutions justify their usefulness by means of their versatility. TE9

(11) Las Redes Neuronales Artificiales (RNA) [Bishop, 2006; Bishop, 1996; Ripley, 1996] son herramientas no lineales que ofrecen una alta eficiencia, siendo capaces de establecer relaciones entre datos de entrada y de salida, [...]. TS4

/Neural networks (NN) [Bishop, 2006; Bishop, 1996; Ripley, 1996] are non-linear tools which provide a high degree of efficiency, enabling links between input and output data to be established [...]. TS4/

To a lesser extent, evaluative verbs with positive value are used to indicate the advantages of the model or approach that is being reviewed. The writer's stance towards the acceptance of the author's results and conclusions is factive (Thompson \& Ye, 1991) with, inter alia, English outperform, highlight, improve, enhance and achieve, and Spanish apoyar, mejorar, posibilitar, demostrar and superar, which reveal the writer's agreement with a prior statement.

(12) Within their experiment, they significantly outperform a baseline run without any query expansion, hence indicating the potentials of query modification in video search. TE7

(13) El protocolo DMSTRP [HUANG06] mejora a BCDCP mediante la construcción de MSTs (Minimum Spanning Trees) en vez de los clubs que conectan los nodos en los clústeres. TS3 /The DMSTRP protocol [HUANG06] outperforms BCDCP via constructing MSTs (Minimum Spanning Trees) instead of clubs connecting nodes in the clusters. TS3/

In Strategy 1C surveying the research-related phenomena, certainty markers reflect the writer's stance towards the validity of the reported information. 
(14) But as long as the system is in a working condition and the participants have been found, on-line evaluation techniques are certainly more accurate than lab-based alternatives. TE10

(15) Aunque EEDUC no incorpore varias mejoras, en cuanto a clustering se refiere, se centra en el problema de los hotpots, dejando patente esfuerzos por solucionar un gran problema de las WSNs. Su mejora respecto a EEUC es palpable pero no muy amplia, aunque en comparación con LEACH obtiene una mejora significativa. TS10

/Although EEDUC does not incorporate several improvements, as far as clustering is concerned, it focuses on the hotpots problem, making efforts for solving an important problem of WSNs evident. Its advance with respect to EEUC is obvious but not very great, although it obtains a significant improvement in comparison with LEACH. TS10/

In Move 2, evaluative lexis of positive value is found in Strategies 2C (asserting confirmative claims about knowledge or research practices surveyed), 2D (asserting the relevancy of the surveyed claims to one's own research), and 2E (abstracting or synthesising knowledge claims to establish a theoretical position or a theoretical framework) to show the writers' acceptance of the items reviewed in Move 1 . The significance, value, contribution and applicability of the surveyed items to their own research are explicitly mentioned.

(16) This review has established that audio feedback can be used successfully to encode data and that there are several extremely effective parameters that can be used. The parameters examined in this review will be used as a basis for the design of the audio crossmodal feedback. TE6

(17) Una opción muy interesante es que sea el propio algoritmo de agrupamiento el que genere los antecedentes y consecuentes de la reglas (Díez et al., 2002a). Esta idea será implementada por el algoritmo que se propone en el capítulo 8 de esta Tesis. TS8

IA very interesting option is to make the grouping algorithm itself generate the antecedents and consequents of the rules (Díez et al., 2002a).This idea will be implemented by the algorithm which is proposed in chapter 8 of this thesis. TS8/

Regarding Move 3, research on RAs has concluded that RA writers evaluate their work. For example, in his corpus of RA introductions written in English in the discipline of software engineering, which is closely related to computing, Anthony (1999) found instances of what he called "evaluation of research" which were realised by stressing the applicability and novelty of the research. Similarly, Shehzad (2009, 2010) found in her corpus of computer science RAs written in English a high number of 
occurrences of statements used to enhance the significance of the work presented. The quantitative results obtained by Martín \& León Pérez (2014) in their comparative study on the rhetorical practices of promotion used in RA introductions written in English and in Spanish in the fields of Health Sciences and Humanities/Social Sciences showed that within the same field of knowledge the English corpus presented a higher degree of rhetorical promotion than the Spanish set in each of the disciplines analysed. However, variation was revealed among subdisciplines, which indicated that international writing conventions of the subdiscipline seemed to have more influence than national cultural factors. In line with these studies, a higher number of occurrences of evaluative statements were found in the English set of LRs than in the Spanish set. But our findings on the $\mathrm{PhD}$ genre indicate that the doctoral writers of the computing LRs under study do not frequently express personal stance towards their own research in Move 3. This attitude can be explained by the different context in which the thesis is situated. The aim of the RA is to achieve international visibility and to obtain the credibility and acceptance of the gatekeepers of the discipline. But the thesis work depends on the assessment of the board of examiners to be granted the doctorate and this leads the doctoral candidates to caution and modesty. The writers of the theses in Spanish, for example, announce their research focuses, designs, aims and theoretical position but remain invisible thanks to the use of passives and impersonalisation:

(18) En el siguiente capítulo se desarrolla un algoritmo de estimación basado en un observador Luenberger cuya matriz de ganancia será determinada considerando las incertidumbres del modelo, debido a los problemas en el conocimiento de la planta, mejorando su convergencia respecto a los desarrollos clásicos. TS6

/In the following chapter an estimation algorithm is developed based on a Luenberger observer whose profit matrix will be determined by considering the uncertainties of the model, due to the problems in knowing the plant, thus improving its convergence with respect to classical/traditional developments. TS6/ 
However, positive evaluative lexis is found in Move 3 in both corpora that reflects their favourable position towards the methodology or approach presented in the study (e.g. English effortless, useful, new, novel, significant, important and effective and Spanish ideal, capaz, apto, potente and importante). Highly valued aspects of the contribution to research are novelty, as pointed out by Anthony (1999), and efficiency:

(19) As part of the evaluation methodology I propose a novel technique to capture the trend of user interests during the profiling process. TE10

(20) La presente tesis hará uso de Toolbox YALMIP [...]. Asimismo se hará uso de la librería Sedumi, la cual implementa un potente algoritmo para la resolución de este tipo de problemas. TS5

/The present thesis will use Toolbox YALMIP [...]. In addition, the Sedumi library will be used, which implements a powerful algorithm for solving this type of problems. TS5/

\subsubsection{Criticising}

Negative critique on the part of the doctoral writer is found in Move 2, where evaluative elements of negative value are used for showing limitations or flaws in previous work and justifying the work presented in the thesis (Ridley, 2011). Although some English-Spanish contrastive studies have concluded that Spanish researchers avoid highlighting the shortcomings of previous studies and therefore omit Move 2 (Moreno, 2010: 60), we found that critical attitude in Move 2 is expressed in the two sets of computing PhD LRs. Counter-factive stance portraying the cited author's judgements as false, incorrect or incomplete serves to establish the niche for the doctoral writer’s own alternative claim (Soler-Monreal \& Gil-Salom, 2014).

According to the data in Table 6, the most common negative devices used in the LRs under study are evaluative adjectives and nouns with negative meanings, adversatives and negative expressions. Two major strategies, Strategy 2A counter- 
claiming and Strategy 2B gap-indicating, are associated with negative evaluation.

Strategy 2A is the most frequent and concentrates many instances of evaluation.

Weaknesses in existing research or knowledge in the field are criticised by means of evaluative adjectives with negative meaning or negative prefixes, often reinforced with intensifiers.

(21) A lot of the papers that were classified as having Any Empirical work had poor levels of empiricism. They mostly involved a simple demonstration of a process or tool to show that it "worked", with very little detail and often without even the most cursory of comparison or analysis with other existing processes or tools that were in the same area. TE2

(22) La caracterización geométrica de [Jiang et al. 99] es incompleta, además de no optimizarse determinados parámetros del aparcamiento. TS3

/[Jiang et al. 99]'s geometrical characterization is incomplete, besides the fact that specific parking parameters have not been optimized. TS3/

(23) De hecho, el punto débil de HECTOR es la propia construcción del árbol de enrutamiento, ya que éste no se construye siguiendo unas pautas de energía residual en los nodos. TS10

/In fact, HECTOR's weakness lies in the construction of the routing tree, since it is not built following instructions about resident energy in the nodes. TS10/

Evaluative nouns refer explicitly to the limitations of the reviewed item such as

English limitation, disadvantage, lack, drawback and controversy and Spanish

desventaja, limitación, inconveniente and restricción.

(24) The lack of textual annotation on video digital libraries prevents the adoption of this approach in video retrieval systems. TE7

(25) Los bioprocesos tienen el inconveniente de que los sensores físicos para la medida en línea de todos los estados no siempre se tienen disponibles. TS6

/Bioprocesses have the inconvenience that the physical sensors for measuring all the states online are not always available. TS6/

A number of evaluative verbs are also used to portray existing research as false, incorrect or incomplete such as English lack, prevent, neglect, rely on, oversimplify, suffer from, limit, question and fail and Spanish violar, distar, perjudicar, minimizar, contradecir, and limitarse.

(26) This approach limits the user's ability to take advantage of problem specific knowledge to improve the constraint model. TE9 
(27) Esto implica mayor memoria y mayor $H W$ decomputación en los propios nodos, lo que contradice el principio fundamental de las WSNs, bajo consumo y bajo coste. TS10

/This involves greater memory and greater HW decomputation in the nodes themselves, which contradicts the fundamental principle of WSNs, low consumption and low cost. TS10/

As for Strategy 2B in Move 2, the indication of a gap or problem is shown through choices related to the gap-problem-need lexical chain.

(28) The need to field a fully engineered system and build up a community of users eager to use a prototype system frequently for long-term studies is the major drawback of user-centred evaluation techniques. TE10

(29) Uno de los problemas de los perceptrones multicapa es el peligro de obtener un modelo sobreentrenado, es decir, un modelo [...] incapaz de ofrecer buenas respuestas para individuos de los que no posee información previa. Por ello, es necesario establecer ciertos mecanismos que controlen el rendimiento ofrecido por el modelo, a fin de detectar cuándo es necesario volver a entrenar la red o cuándo dejar de hacerlo. TS4

/One of the problems of multilayer perceptrons is the risk of obtaining an overtrained model, i.e. a model [...] unable to offer good responses to individuals about whom it lacks previous data. For this reason, it is necessary to establish certain mechanisms for controlling the throughput offered by the model, so as to detect when it is necessary to retrain the network or when to stop doing so. TS4/

Apart from explicitly evaluative attitude markers, discourse-based expressions may also express evaluation when studied in context. The interplay of the cotext and negative expressions in the LRs directly express the writer's opinion and state clearly the criticism.

(30) The original surveys did not measure this, nor did they set out to measure it [73]. TE2

(31) Nevertheless, even this methodology does not address the full complexity and diversity of the ISP. TE8

(32) La propuesta presentada por Hera no aborda cómo se implementan estos servicios Web ni propone un método para derivar servicios Web a partir de los modelos Hera. TS2

/Hera's proposal does not deal with how these Web services are implemented nor does it propose a method for deriving Web services from Hera models. TS2/

(33) Por ello, el autor considera que en lo referente a QoS este protocolo no aporta nada. TS10

/For this reason, the author considers that this protocol does not offer anything as far as QoS is concerned. TS10/

Certainty and epistemic modality markers are also found in Move 2, although they are much less used. Epistemic adverbs (e.g. English possibly and Spanish posiblemente 
and quizá) and modals are particularly used when counter-claiming, so as to soften the writer's critical claim and engage the reader in a dialogue allowing her/him to think differently:

(34) These models of people's movement could possibly be exploited to enhance the epidemic transmission of information between people's mobile devices. TE1

(35) [...] un modelo borroso de este tipo puede ser apropiado para combinar las linealizaciones y llegar a integrarlas en redes de modelos locales o linealizaciones basadas en la velocidad, [...]. Sin embargo, pueden surgir problemas en la interpolación de las reglas (modelos) propuesta en la inferencia TS, tal y como se muestra en el apartado 5.2. TS8

$/[\ldots]$ this type of fuzzy model could be appropriate for combining linearizations and integrating them into local networks of models or linearizations based on speed, [...]. However, problems may arise in the interpolation of the rules (model) proposed in inference TS, as is shown in subsection 5.2. TS8/

\subsubsection{Praising and criticising}

A typical practice of both sets of LRs is to combine positive and negative evaluation to soften the force of the criticism of another researcher's work. This is particularly the case when the writers synthesise the characteristics of models, previous findings, methods or approaches (Move 2 Strategy E). In this case, Move 2 can be considered to be embedded in Move 1, i.e. specific previous achievements are reviewed and the problems they have entailed are also mentioned, so that a complete picture of the state-of-the-art related to the topic is offered. The writer acknowledges the merits of existing approaches but identifies flaws in them, which justifies the work presented in the thesis. With this strategy, the threat to the reviewed authors is mitigated. This results from the combination of evaluative words with opposite meaning, affirmative and negative expressions and adversatives in both corpora. 
(37) The authors do not give a complexity argument for their solutions. However, they do give empirical results of some experiments comparing their model against a distributed version of the EGS algorithm.TE9

(38) A pesar de que el método OO-H no permite el diseño de servicios Web, Visual Wade sí que permite generar la lógica de la aplicación por medio de servicios Web. TS2

/Although the OO-H method does not allow the design of Web services, Visual Wade does allow the generation of the logic of the application by means of Web services. TS2/

(39) La visión tiene algunas ventajas respecto a los otros métodos aunque con el inconveniente del coste computacional asociado al tratamiento de imagen [...]. TS3

/The approach has certain advantages over the other methods despite the inconvenience of the computational cost associated to image treatment [...]. TS3/

\section{Discussion and conclusions}

Evaluation constitutes an essential aspect of the interpersonal in discourse. This study analysed resources of evaluation used by the writers of $20 \mathrm{PhD}$ LRs in computing in English and in Spanish at both rhetorical and linguistic levels.

Kwan's (2006) move structure was used on each LR to identify the rhetorical purpose of all the text fragments. For the semantic/pragmatic analysis, we took as a reference Stotesbury's (2003) and Koutsantoni's (2004) taxonomies and elaborated our own list with the items we identified in the corpus as means of expressing personal attitude and judgement. We focused on four categories of markers: attitude, certainty, epistemic modality and discourse-based markers.

The internationalisation of English as the language of scholarship has caused some general uniformity in text production. In addition, computing is a relatively recent discipline whose achievements have been published in English and which, consequently, is strongly influenced by Anglo-American patterns. This explains why many similarities between the LRs in the two sets of theses were found. However, some differences were also found both in rhetorical and stylistic terms.

The analysis showed that the Move1-Move2-Move3 structure of Kwan’s (2006) model occurs in 10 LRs in the English corpus but in only eight LRs in Spanish. The 
most frequently used cycle is Move1-Move2. This finding coincides with Bunton's (2002) results for PhD thesis introductions in English: writers typically map the territory (Move 1) and point out gaps or problems (Move 2) recursively as they review the literature, but they do not go on to announce their own research (Move 3), which is often done at the beginning and/or end of the chapter and consists mainly in announcing the present research and/or the research aims, focuses and design. The data also corroborate the finding that dedicated LRs of theses follow a similar structure to that of the Introduction chapters of $\mathrm{PhD}$ theses (Thompson, 2009). However, while the Introduction offers a relatively concise context for the research and an outline of the contents of the thesis, the LR explores in more detail related research, discusses theories, concepts and terminology relevant to the topic and highlights the significance of the work done (Ridley, 2011: 88). The cycles in the LR can be seen as the development of the Introduction, aiming to establish a coherent connection between related previous research activity and the current research (Hyland, 2012b: 33).

Examples of all the strategies identified by Kwan in each move together with a new strategy in Move 3 about the contribution of the current research were found in both sets of theses. However, there was some variation as regards the strategies used in each move. The writers in English use a wider range of strategies, especially in Moves 2 and 3.

All the LRs in the corpus use Move 1 Establishing one part of the territory of one's own research. Moreover, Strategy 1A surveying the non-research-related phenomena or knowledge claims and Strategy 1C surveying the research-related phenomena are most commonly used in both sets of LRs. All the LRs in both corpora also use Move 2. In contrast to previous contrastive studies on academic texts written in Spanish and in English suggesting that RA writers in Spanish did not establish the niche 
they intended to occupy (cf. Burgess, 2002), it was found that all the Spanish LRs in the corpus use Move 2, thus reflecting that the Spanish writers in the computing community conform to a great extent to the international rhetorical norms. The writers in both sets of LRs use more than one strategy to create the niche but the English LRs use a wider range of strategies. The five strategies in Move 2 included in Kwan's (2006) model are found in nine English LRs, while only five Spanish theses use all of them. The other English LR uses four different strategies whereas the other five Spanish LRs use only two or three strategies in Move 2.

With regard to Move 3, the results of our analysis, differently to Kwan's (2006), who included it as an optional move in her model, showed that the move is used consistently in the corpus. The ten LRs in English and eight Spanish LRs use it, which may point out the fact that thesis writers in Spanish do not consider it to be an essential component of a LR, although this should be confirmed with the study of a larger corpus. In both sets of LRs Move 3 typically consists of statements at the beginning and at the end of the LR section in which the author mainly announces the research aims or focuses (Strategy 3A) or specifies the research process (Strategy 3C). In addition, although less frequently used, a strategy referring to the thesis contribution to research (Strategy 3E) was identified.

Looking at the most common strategies in the corpus it is possible to establish a parallelism with Ridley's (2011) picture of a LR, which is adequate to describe LRs written both in English and in Spanish. The multiple purposes she recommends to include in a LR review can be easily associated to the most frequently used strategies by the writers in our corpus. Ridley's steps, providing a historical background for the research and giving an overview of the current research, correspond to Move 1 Strategy 
1A. Discussing relevant theories and concepts, introducing terminology and providing definitions are associated with Move 1 Strategy 1C. Describing related research and challenging it coincides with Move 2 Strategy 2A. Addressing a gap in previous research is Move 2 Strategy 2B. Showing that your work extends related research is labeled Move 2 Strategies 2C and 2E. Finally, addressing a particular issue and underlining the significance of the thesis research serves to explain how the niche will be occupied (Move 3). We can add that in the corpus this is done mainly by announcing the research focus, aims and processes (Strategies 3A and 3C).

As a general conclusion of the study, we can say that the differences between the two sets of computing LRs are mainly found in Moves 2 and 3. The writers in English use a wider range of strategies for the development of each move than the writers in Spanish, a result which was also found when comparing English with other cultures, e.g. the Japanese cultural background (cf. Ono, 2012), and which can be explained by different writer/reader relationships in the communication process. Native English writers explicitly establish the relations between propositional contents (thus assuming a responsible role in the act of communication in the texts), while these connections remain partly implicit in the Spanish texts, which seem to transfer the responsibility of interpretation to the reader (Hinds, 1987: 143). The pattern of the computing LRs in English seems to convey a strong sense of competiveness which is less developed in the writers in Spanish. The writers in English appear to show a mercantile mentality (Yakhontova, 2002), which makes them highlight the limitations of existing research and present their own studies as unique worthy products. The writers in Spanish, however, do not "sell" their achievements in such a business-like way or, put in other 
words, they rely on the reader to draw the pertinent conclusions about the value of their contribution.

This should not lead us to conclude, however, that the writers in Spanish lack critical attitude or positioning. In our view, this only reflects different rhetorical practices. Both corpora include attitude markers, certainty markers, epistemic modality and discourse-based markers in the three moves. These resources are used mainly in Moves 1 and 2, both to praise and to criticise previous research. As for Move 3, which announces the work done, the results for the English corpus show both the writer's need to announce the research achievement and her/his desire to proclaim its significance. However, the Spanish set has fewer examples of evaluation in Move 3, which suggests that writers in Spanish downplay their own research contribution and avoid putting themselves forward. This is consistent with previous research on Spanish-English academic discourse which argued that the Spanish community culture values specialised background knowledge but does not focus on emphasising the originality of the work presented (Mur, 2007; Moreno \& Suárez, 2008).

The computing PhD thesis writers in Spanish do not project themselves and distinguish their own voices from those of the cited authors so overtly as the writers in English do. When writing their LRs, Spanish doctoral students are recommended by their supervisors not to sound too aggressive about the work of other researchers of the field and to remain modest, as "creating enemies is not a good strategy...you never know who will be in the board" (personal communication from a Spanish doctoral writer). They leave the responsibility of making inferences about the weaknesses in previous work and deducing about the importance of their contribution to the reader. As Moreno et al. (2012) explain, this rhetorical and stylistic habit is related to the specific forms of socialisation in the disciplinary community of practice in Spanish. Apart from 
the idiosyncratic factor, the strategy shows that the thesis writers in Spanish mingle cautious academic practice with convention to suit their purpose.

Regarding the use of evaluative markers, this article has provided examples found in the LRs in English and in Spanish. Attitude markers are the most usual devices doctoral writers use to express opinion in the two sets. But there are significant differences with certainty, epistemic modality and discourse-based markers. Epistemic modality and a variety of discourse-based markers are typically found in the English LRs while the Spanish LRs seem to rely mainly on adversatives. Few certainty markers have been found in the English corpus in comparison to the percentage of certainty markers found for the writers in Spanish, which may indicate that, unlike the writers in Spanish, the writers in English establish a relationship of deference to the readers, based on the acceptance of alternative opinions. Indeed, the comparison of the percentages of epistemic modality markers shows that their use is almost three times higher in the English corpus than in the Spanish set. The differences respond partly to individual writing styles, but also reflect rhetorical variation in the relationship with the audience (the examiners).

We acknowledge that the study has limitations, principally due to the small corpus, which impedes making generalisations from the results. In the future we intend to corroborate these results with further studies and a larger corpus so as to obtain a wider picture of how judgements of academic value are conveyed in different cultural backgrounds, which could be applied to specific classroom contexts.

Evaluative elements maintain relations among the writer, the reviewed author and the discipline community, and reflect the value system they share. Through different types of evaluation $\mathrm{PhD}$ writers praise and criticise one's and others' contribution so as 
to conform to the conventions of the discipline and be accepted by the discipline community, which is essential to succeed in academic communication. In our view, novice researchers should be sensitive to the mechanisms by which attitude and personal opinion are activated linguistically in academic writing. If they were aware of how a text is structured and organised in relation to its purpose, audience and context, they would be in a better position to intervene successfully in their writings.

The findings of this study provide insights for instruction in adopting a dominant voice or position in PhD theses. In particular, Spanish doctoral students in the area of computing do not receive instruction on academic writing. They usually consult previous models of theses in their discipline and imitate them in their own writings. They also have at their disposal a great amount of the literature on thesis writing in Spanish based on handbooks and guides pedagogically oriented towards the way doctoral students should prepare and conduct research, and focusing on the design, organisation and writing up of theses and dissertations. Their goal is to help students to demonstrate both their knowledge related to the research undertaken and their ability to argue logically and meaningfully about the research findings (e.g. Primo Yúfera, 1994; Rigo \& Genescà, 2002; Castelló et al., 2007; Rivera-Camino, 2011). But these studies do not give any advice on how to develop the writers' critical attitude and position in their writings.

One way for teachers of doctoral/research writing to have critical examinations of the state of the field in literature reviews is to draw on the notions of writer's stance and positioning and explore texts for how personal attitude and judgement are displayed. Academic writing courses should include this evaluation component. By studying interaction in actual texts in a specific language, students would be made aware of the 
importance of arguing successfully and managing evaluative resources skillfully to convince readers of their authority. As novice writers they would be in good condition to incorporate this essential facet of academic communication into their own written production.

\section{References}

Anthony, L. (1999). Writing research article introductions in software engineering. How accurate is a standard model? IEEE Transactions on Professional Communication, 42, 38-46.

Anthony, L. (2001). Characteristic features of research article titles in computer science. IEEE Transactions on Professional Communication, 44, 187-194.

Bhatia, V. K. (2001). Analysing genre: Some conceptual issues. In M. Hewings (Ed.), Academic writing in context: Implications and applications (paper in honor of Tony Dudley-Evans) (pp. 79-92). Birmingham: University of Birmingham.

Bunton, D. (2002). Generic moves in Ph.D. thesis introductions. In J. Flowerdew (Ed.), Academic discourse (pp. 57-75). London: Pearson Education.

Bunton, D. (2005). The structure of PhD conclusion chapters. Journal of English for Academic Purposes, 4, 207-224.

Burgess, S. (2002). Packed houses and intimate gatherings: Audience and rhetorical structure. In J. Flowerdew (Ed.), Academic discourse (pp. 216-232). London: Pearson Education.

Carbonell-Olivares, M., Gil-Salom, L. \& Soler-Monreal, C. (2009). The schematic structure of Spanish PhD thesis introductions. Spanish in Context, 6(2), 151-175.

Castelló, M., Miras, M., Solé, I., Teberosky, A., Iñesta, A. \& Zanotto, M. (2007). Escribir y comunicarse en contextos científicos y académicos: conocimientos y estrategias. Barcelona: Graó.

Charles, M. (2003). "This mystery...” a corpus-based study of the use of nouns to construct stance in theses from two contrasting disciplines", Journal of English for Academic Purposes, 2, 313-326.

Charles, M. (2006). The construction of stance in reporting clauses: A cross-disciplinary study of theses. Applied Linguistics, 27, 492-518.

Charles, M. (2009). Stance, interaction and the rhetorical patterns of restrictive adverbs: Discourse roles of only, just, simply and merely. In M. Charles, D. Pecori and S. Hunston (Eds.), Academic writing. At the interface of corpus and discourse (pp. 152- 169). London/New York: Continuum International Publishing Group.

Cooley, L. \& Lewkowicz, J. (1997). Developing awareness of the rhetorical and linguistic conventions of writing a thesis in English: addressing the needs of EFL/ESL postgraduate students. In A. Duszak (Ed.), Culture and styles of academic discourse (pp. 113-129). Berlin/New York: Mouton de Gruyter.

Cooper, C. (1985). Aspects of article introductions in IEEE publications. MSc unpublished dissertation. Birmingham: The University of Aston in Birmingham.

Duszak, A. (1997). Cross-cultural academic communication: A discourse-community view. In A. Duszak (Ed.), Culture and styles of academic discourse (pp. 11-39). Berlin: Mouton de Gruyter.

Fernández Polo, (1999). Traducción y retórica contrastiva. A propósito de la traducción de textos de divulgación científica del inglés al español. Santiago de Compostela: Servicio de Publicaciones de la Universidad de Santiago de Compostela. 
Fløttum, K., Dahl, T. \& Kinn, T. (2006). Academic voices: Across languages and disciplines. Amsterdam/Philadelphia: John Benjamins Publishing Company.

Flowerdew, J. (2001). Attitudes of journal editors to non-native speaker contributions. TESOL Quarterly, 35, 121-150.

Flowerdew, J. \& Forest, R. (2009). Schematic structure and lexico-grammatical realization in corpus-based genre analysis: The case of research in the $\mathrm{PhD}$ literature review. In $\mathrm{M}$. Charles, D. Pecorari \& S. Hunston (Eds.), Academic writing. At the interface of corpus and discourse (pp. 15-36). New York/London: Continuum.

Gil-Salom, L. \& Soler-Monreal, C. (2010). Appraisal resources in scientific research article discussions. In M-Ll. Gea-Valor, I. García-Izquierdo \& M-J. Esteve (Eds.), Linguistic and translation studies in scientific communication. Linguistic insights. Studies in language and communication (pp.69-89) Vol. 86. Bern: Peter Lang.

Golebiowski, Z. (2011). Scholarly criticism across discourse communities. In F. Salager-Meyer \& B. A. Lewin (Eds.), Crossed words: Criticism in scholarly writing (pp.203-224). Linguistic Insights Series 104. Bern: Peter Lang.

Harwood, N. (2009). An interview-based study of the functions of citations in academic writing across two disciplines. Journal of Pragmatics, 41, 497-518.

Hewings, A., Lillis, T. \& Vladimirou, D. (2010). Who's citing whose writings? A corpus based study of citations as interpersonal resource in English medium national and English medium international journals. Journal of English for Academic Purposes, 9(2), 102-115.

Hinds, J. (1987). Reader versus writer responsibility: A new typology. In U. Connor and R. Kaplan (Eds.), Writing across languages: Analysis of L2 text (pp.141-152). Reading, Massachusetts: Addison-Wesley.

Hu, G. \& Wang, G. (2014). Disciplinary and ethnolinguistic influences on citation in research articles. Journal of English for Academic Purposes, 14, 14-28.

Hunston, S. (1993). Professional conflict: Disagreement in academic discourse. In M. Baker, G. Francis, \& E. Tognini-Bognelli (Eds.), Text and technology: In honour of John Sinclair (pp. 115-134). Amsterdam: John Benjamins.

Hunston, S. (2003). Evaluation and the planes of discourse: Status and value in persuasive texts. In S. Hunston \& G. Thompson (Eds.), Evaluation in text: Authorial stance and the construction of discourse (pp. 176-207). Oxford/New York: Oxford University Press.

Hyland, K. (2000). Disciplinary discourses: Social interactions in academic writing. Harlow, UK: Longman.

Hyland, K. (2002). Activity and evaluation: Reporting practices in academic writing. In J. Flowerdew (Ed.), Academic discourse (pp. 115-130). London: Pearson Education.

Hyland, K. (2004). Engagement and disciplinarity: the other side of evaluation. In G. Del Lungo Camiciotti \& E. Tognini Bonelli (Eds.), Academic discourse-new insights into evaluation (pp. 13-30). Bern: Peter Lang.

Hyland, K. (2012a). Disciplinary identities. Individuality and community in academic discourse. Cambridge: Cambridge University Press.

Hyland, K. (2012b). Undergraduate understandings: Stance and voice in final year reports. In K. Hyland \& C. Sancho Guinda (Eds.) Stance and voice in written academic genres (pp. 135-150). Hampshire: Palgrave Macmillan.

Koutsantoni, D. (2004). Attitude, certainty and allusions to common knowledge in scientific research articles. Journal of English for Academic Purposes, 3, 142-175.

Kuo, C.H. (1999). The use of personal pronouns: Role relationships in scientific journal articles. English for Specific Purposes, 18, 121-138.

Kwan, B. (2006). The schematic structure of literature reviews in doctoral theses of applied linguistics. English for Specific Purposes, 25, 30-55.

Kwan, B. (2008). The nexus of reading, writing and researching in the doctoral undertaking of humanities and social sciences: Implications for literature reviewing. English for Specific Purposes, 27(1), 42-56. 
Kwan, B., Chan, H. \& Lam, C. (2012). Evaluating prior scholarship in literature reviews of research articles: A comparative study of practices in two research paradigms. English for Specific Purposes, 31, 188-201.

Kwan, B. \& Chan, H. (2014). An investigation of source use in the results and the closing sections of empirical articles in Information Systems: In search of a functional-semantic typology for pedagogical purposes. Journal of English for Academic Purposes, 14, 29-47.

Lim, J.M.H. (2012). How do writers establish niches? A genre-based investigation into management researchers' rhetorical steps and linguistic mechanisms. Journal of English for Academic Purposes, 11, 229-245.

Lim, J.M.H, Loi, Ch.K. \& Hashim, A. (2014). Postulating hypotheses in experimental doctoral dissertations on Applied Linguistics: A qualitative investigation into rhetorical shifts and linguistic mechanisms. Ibérica, 27, 121-142.

LoCastro, V. (2008). Long sentences and floating commas: Mexican students' rhetorical practices and the sociocultural context. In U. Connor, E. Nagelhout \& W. V. Rozycki (Eds.), Contrastive rhetoric: Reaching to intercultural rhetoric (pp. 195-217). Amsterdam: John Benjamins.

Mansourizadeh, K. \& Ahmad, U.K. (2011). Citation practices among non-native expert and novice scientific writers. Journal of English for Academic Purposes, 10, 152-161.

Martín-Martín, P. (2003). A genre analysis of English and Spanish research paper abstracts in experimental social sciences. English for Specific Purposes, 22, 25-43.

Martín, P. \& León Pérez, I.K. (2014). Convincing peers of the value of one’s research: A genre analysis of rhetorical promotion in academic texts. English for Specific Purposes, 34, 113.

Mauranen, A. (1993). Cultural differences in academic rhetoric: A textlinguistic study. Frankfurt am Main: Peter Lang.

Moreno, A. I. (2008). The importance of comparable corpora in cross-cultural studies. In U. Connor, E. Nagelhout, \& W. V. Rozycki (Eds.), Contrastive rhetoric: Reaching to intercultural rhetoric (pp. 147-168). Amsterdam: John Benjamins.

Moreno, A. I. (2010). Researching into English for research publication purposes from an applied intercultural perspective. In M.F. Ruiz-Garrido, J.C. Palmer-Silveira \& I. FortanetGómez (Eds.), English for Professional and Academic Purposes (pp. 57-71). Amsterdam. Rodopi.

Moreno, A. I. \& Suárez, L. (2008). A study of critical attitude across English and Spanish academic book reviews. Journal of English for Academic Purposes, 7, 15-26.

Moreno, A. I., Rey-Rocha, J., Burgess, S. López-Navarro, I. \& Sachdev, I. (2012). Spanish researchers' perceived difficulty writing research articles for English-medium journals: the impact of proficiency in English versus publication experience. Ibérica, 24, 157-184.

Mur Dueñas, P. (2007). A contribution to the international analysis of metadiscourse in business management research articles in English and in Spanish: A corpus-driven approach. Unpublished doctoral dissertation. Universidad de Zaragoza, Zaragoza (Spain).

Myers, G. (1990). Writing biology. Texts in the social construction of scientific knowledge. Winconsin: The University of Winconsin Press.

Ono, M. (2012). A genre analysis of Japanese and English introductory chapters of Literature $\mathrm{PhD}$ theses. In C. Berkenkotter, V.K. Bhatia \& M. Gotti (Eds.), Insights into academic genres (pp. 191-214). Bern. Peter Lang.

Paltridge, B. (2002). Thesis and dissertation writing: An examination of published advice and actual practice. English for Specific Purposes, 21, 125-143.

Paltridge, B. \& Starfield, S. (2007). Thesis and dissertation writing in a second language. London \& New York: Routledge.

Pecorari, D. (2006). Visible and occluded citation features in postgraduate second-language writing. , English for Specific Purposes, 25, 4-29. 
Peters, S. (2011). Asserting or deflecting expertise? Exploring the rhetorical practices of master's theses in the philosophy of education, English for Specific Purposes, 30, 176185.

Petrić, B. (2007). Rhetorical functions of citations in high-and-low-rated master's theses. Journal of English for Academic Purposes, 6, 238-353.

Posteguillo, S. (1995). Genre analysis for computer science. Unpublished PhD thesis. Valencia: Universidad de Valencia.

Posteguillo, S. (1999). The schematic structure of computer science research articles. English for Specific Purposes, 18, 139-160.

Primo-Yúfera, E. (1994). Introducción a la investigación científica y tecnológica. Madrid: Alianza D.L.

Ridley, D. (2000). The different guises of a $\mathrm{PhD}$ thesis and the role of a literature review. In P. Thompson (Ed.), Patterns and perspectives: Insights into EAP writing practice (pp. 6176). Reading: University of Reading.

Ridley, D. (2011). The Literature review. A step-by-step guide for students. (2nd ed.). London: Sage Publications.

Rigo, A. \& Genescà, G. (2002). Cómo presentar una tesis y trabajos de investigación. Barcelona: Eumo.

Rivera-Camino, J. (2011). Cómo escribir y publicar una tesis doctoral. Madrid: ESIC.

Shaw, P. (2003). Evaluation and promotion across languages. Journal of English for Academic Purposes, 2, 343-357.

Shehzad, W. (2006). Computer scientist's approach to 'Establishing a Research Territory'. Selected papers from the fifteenth international symposium on English teaching. Taipei: Crane Publishing and ETA-ROC.

Shehzad, W. (2007). Explicit author in scientific discourse: A corpus-based study of the author's voice. Malaysian Journal of ELT Research, 3, 56-73.

Shehzad, W. (2008). Move two: Establishing a niche. Ibérica, 15, 25-49.

Shehzad, W. (2010). Announcement of the principal findings and value addition in Computer Science research papers. Ibérica, 19, 97-118.

Sheldon, E. (2011). Rhetorical differences in RA introductions written by English L1 and L2 and Castilian Spanish L1 writers. Journal of English for Academic Purposes, 10, 238-251.

Soler-Monreal, C., Carbonell-Olivares, M. \& Gil-Salom, L. (2011a). A contrastive study of the rhetorical organisation of English and Spanish $\mathrm{PhD}$ thesis introductions. English for Specific Purposes, 30(1), 4-17.

Soler-Monreal, C. \& Gil-Salom, L. (2011b). A Cross-language study on citation practice in PhD theses. International Journal of English Studies, 11(2), 53-75.

Soler-Monreal, C. \& Gil-Salom, L. (2014). Academic voices and claims: Reviewing practices in research writing. In L. Gil-Salom \& C. Soler-Monreal (Eds.), Dialogicity in written specialised genres (pp. 23-54). Amsterdam: John Benjamins.

Stotesbury, H. (2003). Evaluation in research article abstracts in the narrative and hard sciences. Journal of English for Academic Purposes, 2, 327-341.

Swales, J. (1990). Genre analysis. Cambridge: Cambridge University Press.

Thetela, P. (1997). Evaluated entities and parameters of value in academic research articles. English for Specific Purposes, 16(2), 101-118.

Thompson, P. (2001). A pedagogically-motivated corpus-based examination of PhD theses: macrostructure, citation practices and uses of modal verbs. Unpublished doctoral dissertation. Reading: University of Reading.

Thompson, P. (2005a). Points of focus and position: Intertextual reference in $\mathrm{PhD}$ theses. Journal of English for Academic Purposes, 4, 307-323.

Thompson, P. (2005b). Aspects of identification and position in intertextual reference in $\mathrm{PhD}$ theses. In E. Tognini-Bonelli \& G. Del Lungo Camiciotti (Eds.), Strategies in academic discourse (pp. 31-50). Amsterdam: John Benjamins. 
Thompson, P. (2009). Literature reviews in applied $\mathrm{PhD}$ theses: Evidence and problems. In K. Hyland and G. Diani (Eds.), Academic evaluation: Review genres in university settings (pp. 50-67). Basingtoke/New York: Palgrave Macmillan.

Thompson, P. (2012). Achieving a voice of authority in PhD theses. In K. Hyland \& C. Sancho Guinda (Eds.) Stance and voice in written academic genres (pp. 119-133). Hampshire: Palgrave Macmillan.

Thompson, P. \& Tribble, C. (2001). Looking at citations: Using corpora in English for Academic Purposes. Language Learning \& Technology, 5(3), 91-105.

Thompson, G. \& Ye, Y. (1991). Evaluation in the reporting verbs used in academic papers. Applied Linguistics, 12, 365-382.

Vassileva I. (2001). Commitment and detachment in English and Bulgarian academic writing. English for Specific Purposes, 20, 83-102.

Vázquez, L. (2010). A contrastive analysis of the use of modal verbs in the expression of epistemic stance in business management research articles in English and Spanish. Ibérica, 19, 77-96.

Yakhontova, T. (2002). 'Selling' or 'telling'? The issue of cultural variation in research genres. In J. Flowerdew (Ed.), Academic discourse (pp. 16-232). London: Pearson Education.

Appendix. Examples of rhetorical strategies in the English and the Spanish LRs

\begin{tabular}{l}
\hline Move $1 \quad$ Establishing one part of the territory of one's own research \\
\hline Strategy A: surveying the non-research-related phenomena or knowledge claims \\
\hline Auditory display is an umbrella term referring to the use of any type of sound to present information \\
to a listener. This may include, but is certainly not limited to warnings, alarms, status indicators, and \\
data sonification [152]. TE6 \\
La mayor parte de los robots manipuladores son brazos articulados y tradicionalmente se modelan, \\
desde el punto de vista cinemático, con matrices de transformación homogénea entre sistemas de \\
coordenadas. TS3 \\
/Most manipulating robots are articulated arms and are traditionally modeled, from a kinematic \\
perspective, with matrices of homogeneous transformation between coordinate systems. TS3/ \\
\hline Strategy B: claiming centrality \\
\hline Appropriation is a powerful concept in technology design; it enables users to make use of past \\
experience gained from social interactions, observations and other interactions with objects and \\
technology. It is for this reason that appropriation is extremely important to impression management. \\
TE5
\end{tabular}

Un tema de especial importancia es la interpretabilidad del modelo borroso obtenido pues, como se ha comentado, esta es la característica más reseñable de los sistemas inteligentes y no su capacidad de aproximadores universales. TS8/

/A specially important issue is the interpretability of the fuzzy model obtained since, as has been commented upon, this is the most relevant characteristic of intelligent systems and not their capability as universal aproximators. TS8/

Strategy C: surveying the research-related phenomena

In 1999, Bessiere et al. proposed AC7 [17], which improves on AC6 by exploiting the bidirectional nature of support values over a binary constraint, meaning that $(a ; b) 2$ Cxy iff $(b ; a) 2$ Cyx. TE9

En este trabajo, Foster y colaboradores presentan Gara [23], una arquitectura para la gestión de recursos distribuidos construida sobre Globus Toolkit. TS1

/In this work, Foster and his collaborators present Gara [23], an architecture for the management of distributed systems built on Globus Toolkit. TS1/

\begin{tabular}{ll}
\hline Move 2 & Creating a research niche (in response to $\mathbf{M}$ 1) \\
\hline Strategy A: & counter-claiming \\
\hline
\end{tabular}


This approach is based on the assumption that the user's information interest is static, which is, however, not appropriate in a retrieval context. TE7

La propuesta presentada por Hera no aborda cómo se implementan estos servicios Web ni propone un método para derivar servicios Web a partir de los modelos Hera. TS2

/Hera's proposal does not deal with how these Web services are implemented nor does it propose a method for deriving Web services from Hera models. TS2/

Strategy B: gap-indicating

Even though weighted keyword profiling has been well studied in the text domain, hardly any work has been done on studying similar approaches in the video domain. TE7

Por ello se hace necesario la introducción de métodos que proporcionen soluciones factibles y de buena calidad en tiempos de cómputo razonable. TS7

/Thus it is necessary to introduce methods providing feasible and high quality solutions in reasonable computing time.TS7/

Strategy C: asserting confirmative claims about knowledge or research practices surveyed

The advantage of this approach is that side constraints can be added to allow richer problems to be solved. This lends this approach the versatility of the general architecture of a CSP. TE9

Por tanto, gracias a seguir una estrategia basada en SRM, las SVM ofrecen buenos resultados al enfrentarse a nuevos datos, ofreciendo modelos capaces de generalizar de forma adecuada. TS4 /Thus, thanks to a SRM-based strategy, SVMs provide good results when facing new data, offering models capable of making generalisations adequately. TS4/

Strategy D: asserting the relevancy of the surveyed claims to one’s own research

The effect rendering speed has on filtering out detail and revealing overview information will be taken as one of the bases for the solution proposed and investigated in this thesis. TE3

Afortunadamente, existen algunas técnicas que permiten la linealización en torno a puntos que no son de equilibrio, como la linealización en torno a puntos de operación (Hunt and Johansen, 1997) o la linealización basada en la velocidad (Leith and Leithead, 2000; Rugh and Shamma, 2000). Dichas técnicas son las más apropiadas en el marco de esta Tesis y son comentadas en este capítulo. TS8 /Fortunately, there exist some techniques that allow linearization around points that are not breakeven points, such as linearization around operating points (Hunt and Johansen, 1997) or linearization based on speed (Leith and Leithead, 2000; Rugh and Shamma, 2000). Such techniques are the most appropriate in the framework of this thesis and are commented upon in this chapter. TS8/

Strategy E: abstracting or synthesizing knowledge claims to establish a theoretical position or a theoretical framework

Finally, we introduced different approaches of user profiling. User profiling is one of the key challenges in adaptive search and recommendation. As we discussed, two types of user profiling exist: short-term and long-term profiling. Within this thesis, we will employ both approaches to study the use of implicit relevance feedback in the video domain. TE7

Vistas las diferentes opciones para realizar particiones de modelos locales de sistemas no lineales mediante linealización en el entorno de puntos de operación empleando el Jacobiano de la planta, las opciones que se muestran más interesantes y por tanto se han revisado en este capítulo son las relacionadas con familias de linealizaciones en torno a puntos de operación. TS8

/Given the different alternatives to carry out partitions of local models of non-linear systems through linearization in the environment of operating points using the plant Jacobian, the most interesting options which consequently have been reviewed in this chapter are those related to families of linearizations around operating points. TS8/

\begin{tabular}{l} 
Move $3 \quad$ Occupying the research niche by announcing \\
\hline Strategy A: research aims, focuses, research questions or hypotheses \\
\hline Within this thesis, we will focus our research on news video retrieval, since this is very content reach \\
video material. TE7 \\
La tesis que defiende este trabajo consiste en que un experto, auxiliado con esta herramienta, puede \\
decidir de entre un grupo de candidatos caracterizados previamente, qué servicios podrán combinarse \\
con éxito en un flujo de trabajo. TS1
\end{tabular}


/The thesis of this work is that an expert, aided by this tool, can determine which services will combine successfully in a work flow among a group of previously characterized candidates. TS1/

Strategy B: theoretical positions/theoretical frameworks

Even though they do not conduct a simulation-based evaluation, their evaluation framework can be seen as a guideline on how to perform user simulations. TE7

Dichas técnicas son las más apropiadas en el marco de esta Tesis y son comentadas en este capítulo. TS8

/Such techniques are the most appropriate in the framework of this thesis and are commented upon in this chapter. TS8/

Strategy C: research design/processes

The work in this thesis makes use of tactile/cutaneous feedback through mechanical stimulation because kinaesthetic feedback is not so appropriate for mobile usage. TE6

La presente tesis hará uso de Toolbox YALMIP que proporciona una interfaz muy intuitiva para la definición de LMIs en el entorno Matlab. Asimismo se hará uso de la librería Sedumi, la cual implementa un potente algoritmo para la resolución de este tipo de problemas. TS5

/The present thesis will use Toolbox YALMIP which provides a very intuitive interface for the definition of LMIs in the Matlab environment. Besides, the Sedumi library will be used, which implements a powerful algorithm for solving this type of problems. TS5/

Strategy D: interpretations of terminology used in the thesis

Given the confusion over the naming and attribution of work categories, I feel it is incumbent on me to make clear what I consider the various categories to be. [...] As a result, from this point on, I will be using the terms Perfective, Adaptive, Corrective, Preventative in reference to this classification system. TE2

[...] se han repasado algunas de las acepciones más relevantes en la literatura referentes al diseño de controladores predictivos borrosos. Asimismo, se ha diferenciado entre las distintas acepciones que presenta dicho término y se ha establecido qué se empleará en el resto de trabajo. Por tanto, el concepto de controlador predictivo borroso que se empleará, hace referencia a aquellos controladores que emplean modelos TS como predictores y además plantean la resolución de problemas de optimización convexos para calcular la ley de control. TS5

/[...] some of the most relevant terms used in the literature for the design of fuzzy predictive controllers have been reviewed. Besides, distinctions have been made about the different meanings of this term and which ones will be used in the rest of this work have been settled. Consequently, the concept of fuzzy predictive controller that will be used refers to controllers that employ TS models as predictors and also propose to solve convex optimisation problems to calculate the control law. TS5/

Strategy E: contribution to research*

Crossmodal feedback may be able to provide a greater amount of feedback using different combinations of tactile and audio. Crossmodal feedback will also allow the user to choose whatever modality is most appropriate given their situation or preference. TE6

[...] teniendo en cuenta los resultados obtenidos en simulación, el diseño presentado en este artículo permite el control de la pa que reducirá la proliferación de NOx. TS5

$/[\ldots]$ bearing in mind the simulation results, the design presented in this article permits the control of the $p a$ that will reduce the proliferation of NOx. TS5/

*new strategy 